\title{
Analysis of Electromagnetic Force in Rough Cutting of Wire-EDM
}

\author{
Shunsuke TOMURA *, Masanori Kunieda *
}

(Received March 15, 2008)

\begin{abstract}
* Department of Mechanical Systems Engineering, Tokyo University of Agriculture and Technology, Tokyo 184-8588, Japan
\end{abstract}

\begin{abstract}
This paper describes changes in the electromagnetic force applied to the wire electrode with increasing depth of cut in wire electrical discharge machining (WEDM). In this study, the electromagnetic force was analyzed by finite element method (FEM). Vibration of the wire when the electromagnetic force was applied to the wire independently was also analyzed. The wire movement was then measured when the current in the wire was changed in the same way as the discharge current with the gap voltage between the wire and workpiece kept at zero. It was found that the electromagnetic force is repulsive when the workpiece material is copper and attractive when the workpiece is steel. In both cases, the force is maximum when the depth of cut is about equal to or smaller than the wire diameter. Compared with the impulse of the electrostatic force, the impulse of the electromagnetic force is even larger in rough cutting.
\end{abstract}

Key words: wire-EDM, electromagnetic field analysis, electromagnetic force, electrostatic force

\section{INTRODUCTION}

In wire-EDM (WEDM), four kinds of forces are applied to the wire electrode ${ }^{1), 2}$ : discharge reaction force ${ }^{1), 3)-6)}$ caused by rapid expansion of a bubble at the discharge spot, electrostatic force ${ }^{1), 4), 6), 7)}$ applied during the ignition delay time, electromagnetic force $^{1,7)}$ caused by the discharge current flowing through the wire, arc column, and workpiece in a series during the discharge duration, and hydrodynamic force ${ }^{8)}$ due to the flushing flow of dielectric fluid. These forces cause the vibration and deflection of the wire electrode, resulting in deteriorated machining accuracy, speed, and stability $^{2), 9)}$.

With regard to electromagnetic force, Panschow ${ }^{1)}$ reported that electromagnetic force caused by a consecutive pulse discharge current can be obtained by summation of the contributions from the DC and $\mathrm{AC}$ components in the Fourier transformation of the discharge current waveform. Electromagnetic force due to DC component of the discharge current is attractive, and Panschow calculated it using the principle of mirror image for workpiece materials with high permeability like mild steel. He calculated electromagnetic forces due to AC components of the discharge current in experiments measuring wire deflection when a current with known frequency and amplitude was supplied to the wire. In the experiments, since electric potentials of the wire and workpiece were equal, only the electromagnetic force was applied to the wire independently. Thus, he found that with steel workpiece, the force was attractive with low frequency but changed to repulsive with increasing frequency. In the case of brass workpiece whose permeability is small, the force was always repulsive and increased with increasing frequency. Obara et al. ${ }^{7}$ also found experimentally that the electromagnetic force is small and repulsive when the workpiece is a paramagnetic material like copper and attractive when the workpiece is ferromagnetic like steel. However, to date, there are no reports on the calculation of electromagnetic force considering electromagnetic induction due to AC components.

Hence, Tomura et al. ${ }^{10)}$ calculated electromagnetic force taking into consideration electromagnetic induction by 2 -dimensional finite element method (FEM). With copper workpiece, the electromagnetic force due to the DC component (static force) was negligible, consequently, the force caused by the electromagnetic induction (dynamic force) was dominant. The dynamic force was repulsive when current in the wire was rising, and attractive when the current was falling. In contrast, with ferromagnetic steel workpiece, the static force was dominant. Hence, the total electromagnetic force was attractive. However, it should be borne in mind that they measured and analyzed the force when the wire electrode faced a flat surface of the workpiece only. Hence, in this study, changes in the electromagnetic force with increasing depth of cut in rough cutting were investigated.

\section{ANALYSIS OF ELECTROMAGNETIC FORCE DURING ROUGH CUTTING}

In rough cutting, the wire faces a flat surface of the workpiece at the beginning, and later the wire is located in a groove as cutting progresses. Fig. 1 


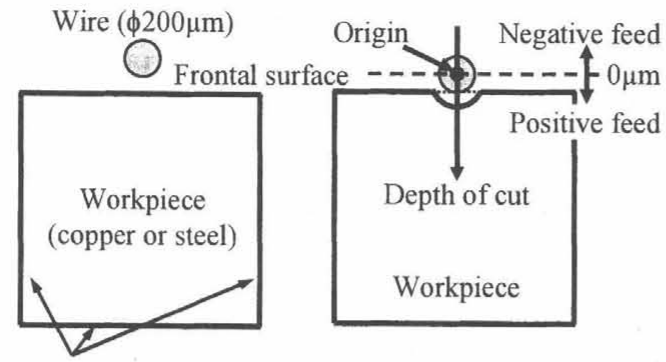

Side surfaces

(a)

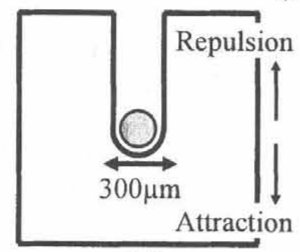

(c)

Fig.1 Model of wire and workpiece used for FEM analysis

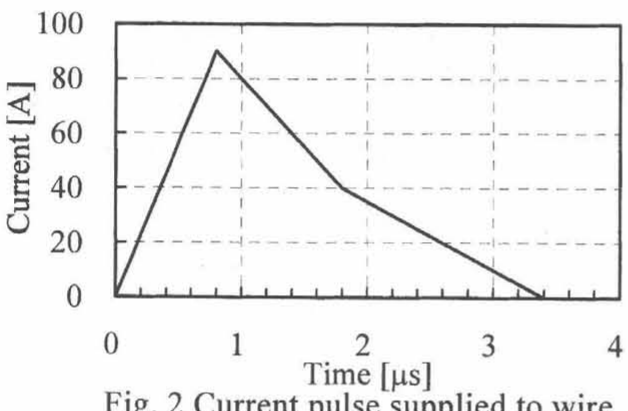

shows the model used to calculate the electromagnetic force with increasing depth of cut: (a) the wire is facing a flat surface of the workpiece, (b) the wire is located in a shallow cut groove, and (c) deep groove. It was assumed that the diameter of the wire is $200 \mu \mathrm{m}$, the width of the cut groove is $300 \mu \mathrm{m}$, and both frontal and side gap widths are $50 \mu \mathrm{m}$. The location where the wire side surface makes contact with the initial flat surface of the workpiece before cutting was defined as the origin of wire position as shown in Fig. 1 (b). When the wire was inside the groove, the wire position was positive and nearly equal to the depth of cut. The distance between the side surfaces and the groove is larger than $2 \mathrm{~mm}$ because smaller distances influenced the force calculated. To determine the permeability and conductivity in the analysis area, it was assumed the wire is made of brass, workpiece is made of steel or copper, and atmosphere around the wire is air. Assuming that a current waveform normally used in rough cutting shown in Fig. 2 is supplied to the wire, a 2-dimensional FEM program for unsteady

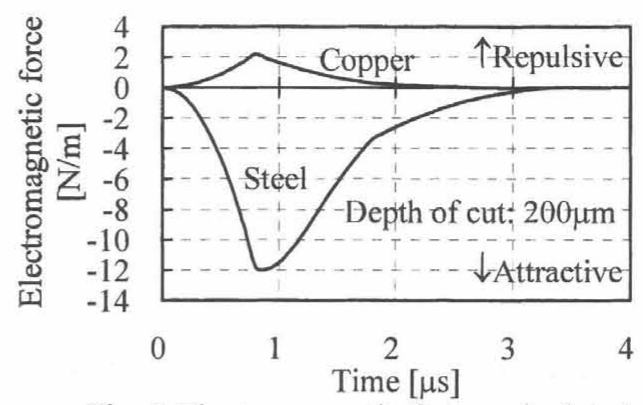

Fig. 3 Electromagnetic force calculated (workpiece: $6 \mathrm{~mm}$ square, depth of cut: $200 \mu \mathrm{m}$ )

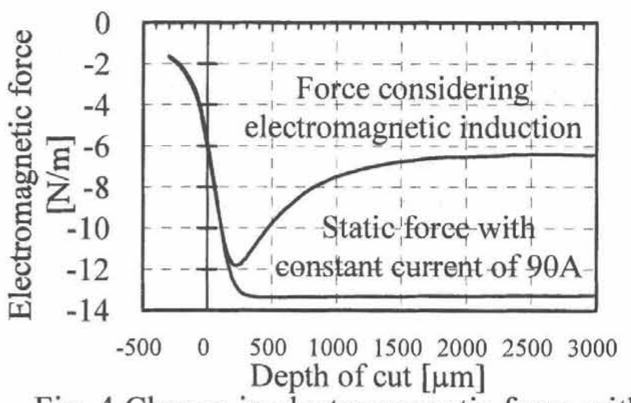

Fig. 4 Change in electromagnetic force with depth of cut when workpiece is steel

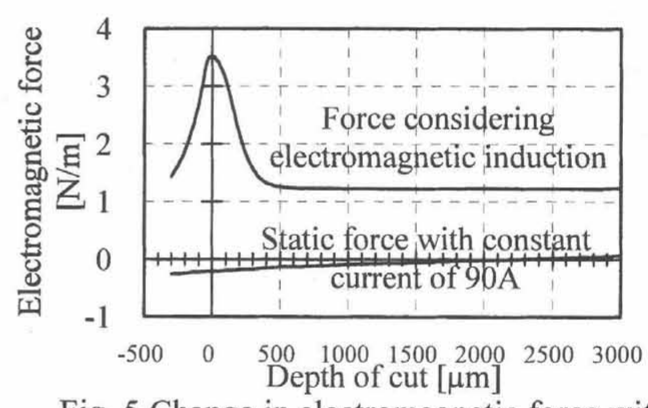

Fig. 5 Change in electromagnetic force with depth of cut when workpiece is copper

electromagnetic field analysis was developed and executed considering the electromagnetic induction.

Changes in the electromagnetic force applied to the wire per unit length were calculated as shown in Fig. 3, when the size of the workpiece was $6 \mathrm{~mm}$ square and the depth of cut was $200 \mu \mathrm{m}$. In the case of steel workpiece, the attractive static force was dominant. In the case of copper workpiece, the repulsive dynamic force was dominant due to the eddy current induced by the rising current. The forces are maximum when the discharge current waveform shows its maximum. Next, changes in the maximum electromagnetic force were calculated with increasing depth of cut. Fig. 4 and Fig. 5 shows the results when the workpiece is steel and copper, respectively. The static electromagnetic forces obtained without considering the 
electromagnetic induction when the current is constant at $90 \mathrm{~A}$ are also shown in Fig. 4 and Fig. 5. Subtracting the static force from the force giving consideration to electromagnetic induction, the contribution of the dynamic force to the total electromagnetic force can be estimated.

With steel workpiece, the influence of the static force is larger than that of the dynamic force, and the resultant electromagnetic force is attractive. The static force increases until the depth of cut reaches the diameter of the wire and remains constant thereafter. However, the dynamic force keeps increasing until the depth of cut reaches $3 \mathrm{~mm}$. Hence, the resultant electromagnetic force takes its maximum value at the depth of cut equal to $200 \mu \mathrm{m}$ and remains constant where the depth of cut is over $2 \mathrm{~mm}$.

In contrast, the static force is negligibly small in copper workpiece. The dynamic force caused by the electromagnetic induction is dominant and repulsive. When the depth of cut is about $0 \mu \mathrm{m}$, the force is largest, and then decreases with the depth of cut. When the depth of cut is over $1 \mathrm{~mm}$, the force is constant independent of the depth of cut.

Impulse applied to unit length of the wire per pulse can be calculated by integrating the electromagnetic force in Fig. 3 with time. With steel workpiece, the impulse was maximum $1.3 \times 10^{-5} \mathrm{Ns} / \mathrm{m}$ at depth of cut of $200 \mu \mathrm{m}$. The impulse was constant, where the depth of cut was over several micrometers. On the other hand, impulse caused by the electrostatic force can be obtained by multiplying the electrostatic force with the discharge delay time. Using the electrostatic force obtained by Obara et al. ${ }^{11)}$, the impulse was calculated as $8.7 \times 10^{-6} \mathrm{Ns} / \mathrm{m}$, assuming that open voltage is $100 \mathrm{~V}$ and discharge delay time is $30 \mu \mathrm{s}$. Hence, the impulse of the electromagnetic force is even larger than that of the electrostatic force under the conditions used in the present work. The copper workpiece showed smaller absolute value of the electromagnetic force than steel workpiece, indicating that the impulse of electromagnetic force is insignificant in copper workpiece. However, even a small impulse can result in wire vibration with large amplitude when the impulse is applied consecutively $^{10)}$.

\section{WIRE MOVEMENT CAUSED ELECTROMAGNETIC FORCE}

To validate the electromagnetic force calculated, wire movement was measured under the condition that only electromagnetic force is applied to the wire. On the other hand, wire movement was analyzed assuming that the electromagnetic force generated by the same current used in the

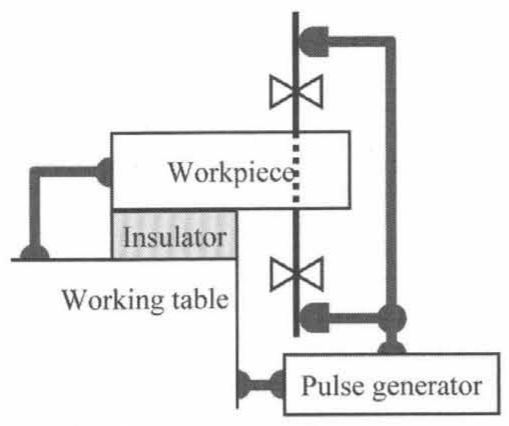

(a) Preparation of groove

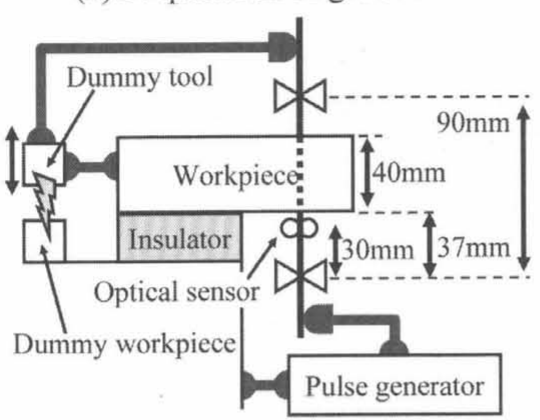

(b) Measurement of wire movement

Fig. 6 Experimental setup to measure wire movement

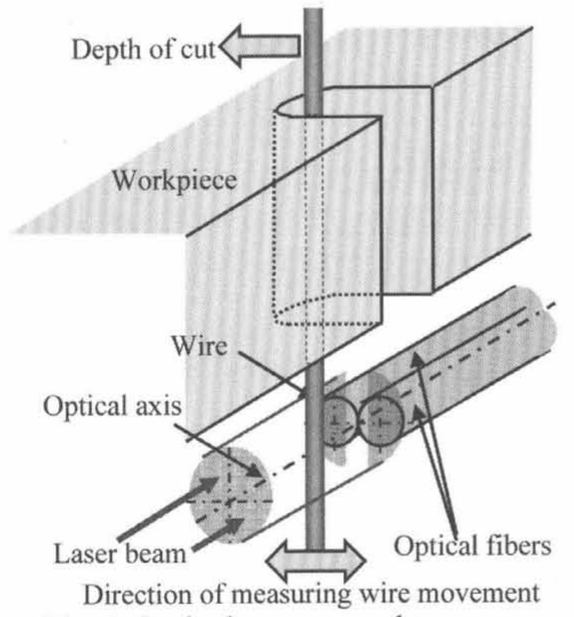

Fig. 7 Optical sensor used to measure wire movement

experiment was applied to the wire.

\subsection{Measurement of wire movement}

It was necessary to measure the wire movement when electromagnetic force alone was applied to the wire without influence by electrostatic force or reaction force due to discharge. For this reason, the experimental method shown in Fig. 6 was used.

First, a groove was machined using WEDM with a depth of cut where wire movement was to be measured, as shown in Fig. 6 (a). In this step, since the workpiece and working table were isolated beforehand, they were short-circuited to the 


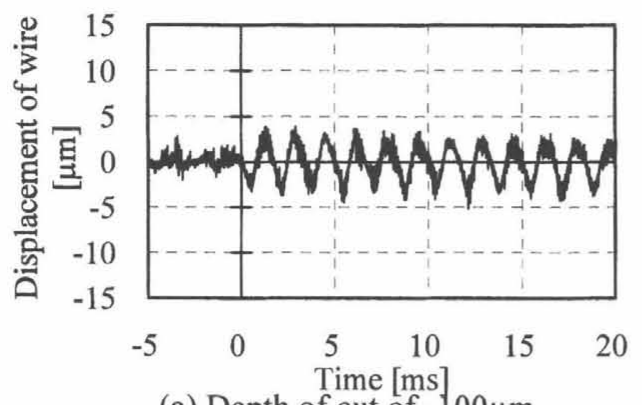

(a) Depth of cut of $-100 \mu \mathrm{m}$

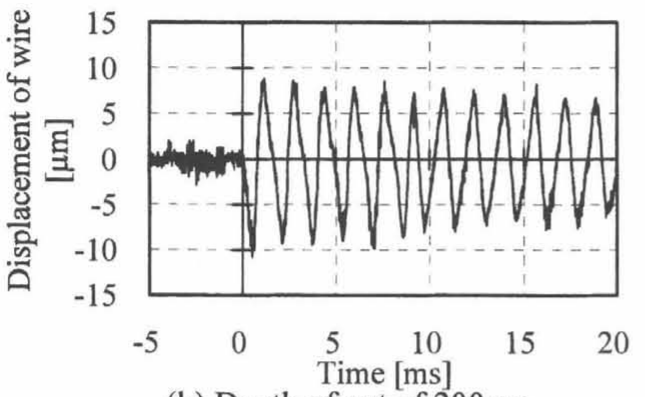

(b) Depth of cut of $200 \mu \mathrm{m}$

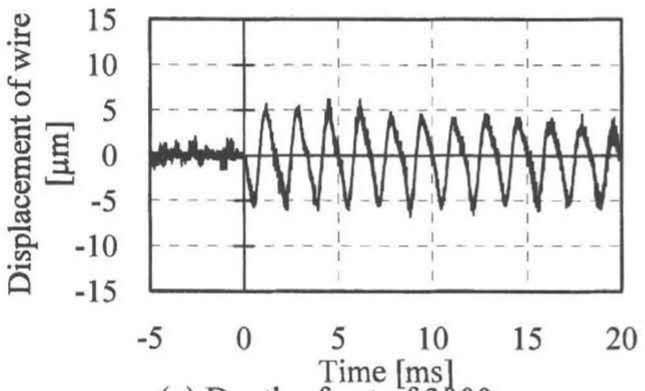

(c) Depth of cut of $3000 \mu \mathrm{m}$

Fig. 8 Wire movement measured when workpiece is steel

working table using a conductive wire. To prepare the groove whose width was $300 \mu \mathrm{m}$ and end radius was $150 \mu \mathrm{m}$, finish cutting was performed after rough cutting. Next, the circuit was rewired as shown in Fig. 6 (b) to measure the movement of the wire to which only electromagnetic force was applied. Since the workpiece was isolated from the work table and short-circuited to the wire electrode, discharge did not occur or the electrostatic force was not applied between the wire and workpiece. Next, a single pulse discharge was generated between the dummy tool electrode and dummy workpiece which were connected to the wire electrode and the pulse generator of the WEDM machine in a series. The gap width between the dummy tool electrode and workpiece was adjusted manually. Thus electromagnetic force alone was applied to the wire.

Wire movement was measured using an optical

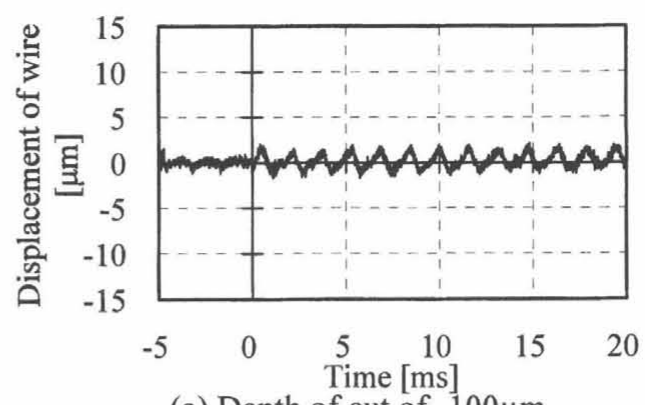

(a) Depth of cut of $-100 \mu \mathrm{m}$

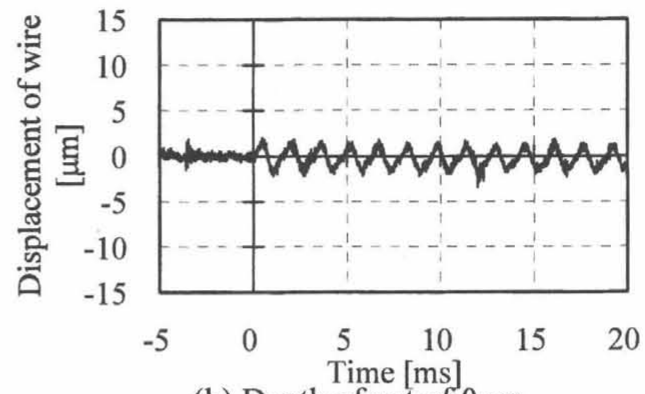

(b) Depth of cut of $0 \mu \mathrm{m}$

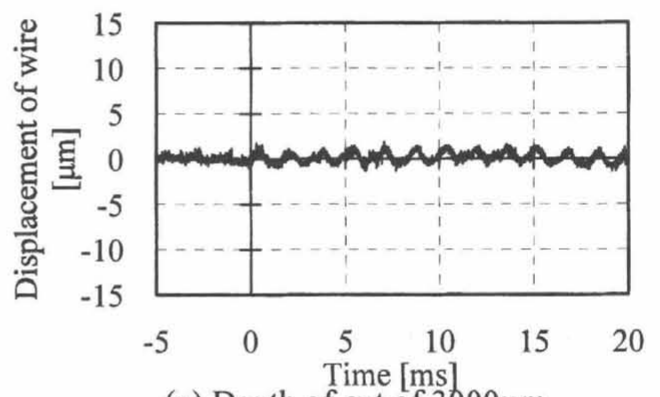

(c) Depth of cut of $3000 \mu \mathrm{m}$

Fig. 9 Wire movement measured when workpiece is copper

sensor developed by Nishikawa et al. ${ }^{12}$ for in-process measurement of wire vibration. The principle of the sensor is shown in Fig. 7. The wire movement in the direction of depth of cut was measured. A collimated laser beam is irradiated incident to two optical fibers arranged in parallel side by side, projecting the silhouette of the wire on the end surfaces of the optical fibers. From the difference in the light intensity received by the fibers, displacement of the wire can be measured with a resolution of $1 \mu \mathrm{m}$.

In the experiment, steel and copper were used as the workpiece materials. Wire movements were measured at the depth of cut of $-100 \mu \mathrm{m}, 200 \mu \mathrm{m}$, and $3000 \mu \mathrm{m}$ in the case of steel workpiece. Depth of cut of $-100 \mu \mathrm{m}$ indicates the situation whereby the wire is facing a flat workpiece with a gap width of $100 \mu \mathrm{m}$ before the start of machining. Depth of cut of $200 \mu \mathrm{m}$ was selected because the 


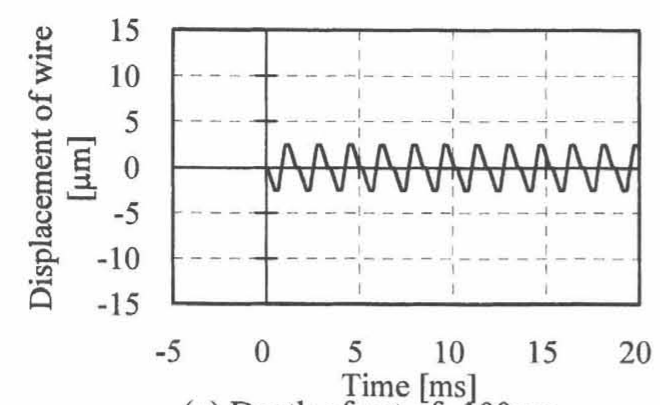

(a) Depth of cut of $-100 \mu \mathrm{m}$

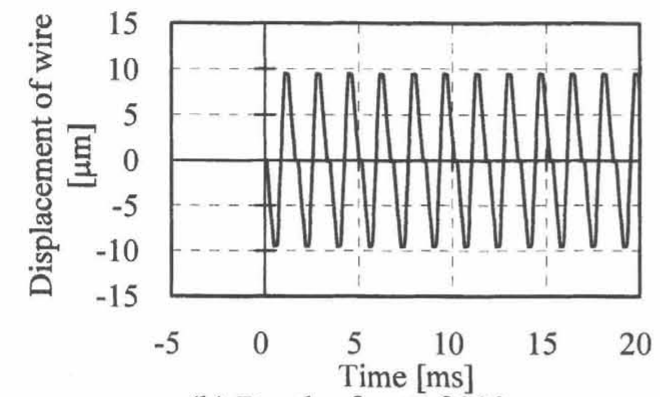

(b) Depth of cut of $200 \mu \mathrm{m}$

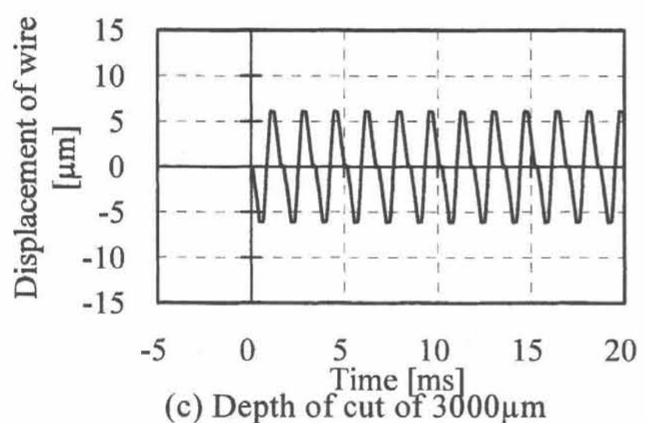

Fig. 10 Wire movement calculated when workpiece is steel

electromagnetic force was largest at this position with the steel workpiece. At depth of cut of $3000 \mu \mathrm{m}$, the electromagnetic force was constant independent of the depth of cut. When the workpiece was copper, wire movement was measured at the depth of cut of $0 \mu \mathrm{m}$ in place of $200 \mu \mathrm{m}$, because the electromagnetic force was largest at $0 \mu \mathrm{m}$. Discharge current was the same as in Fig. 2. The distance between the upper and lower wire guides was $90 \mathrm{~mm}$. The wire tension was $3 \mathrm{~N}$, workpiece thickness was $40 \mathrm{~mm}$, and the distance along which the wire faced the workpiece was from $37 \mathrm{~mm}$ to $77 \mathrm{~mm}$ above the lower guide. Wire movement was measured at $30 \mathrm{~mm}$ above the lower guide as shown Fig. 6.

\subsection{Results of measurement}

Wire movements measured at the depth of cut of $-100 \mu \mathrm{m}, 200 \mu \mathrm{m}$, and $3000 \mu \mathrm{m}$ in the case of steel workpiece are shown in Fig. 8 (a), (b), and (c),

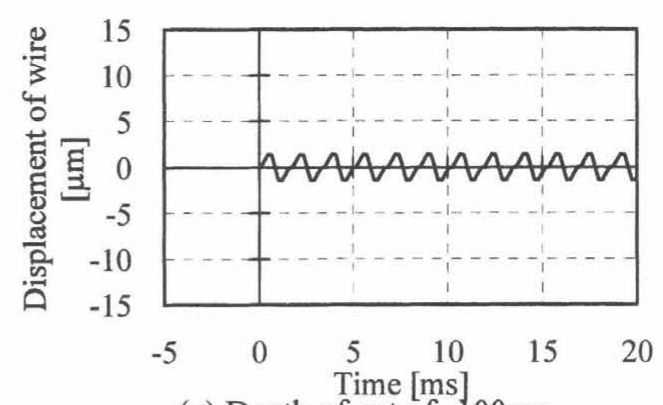

(a) Depth of cut of $-100 \mu \mathrm{m}$

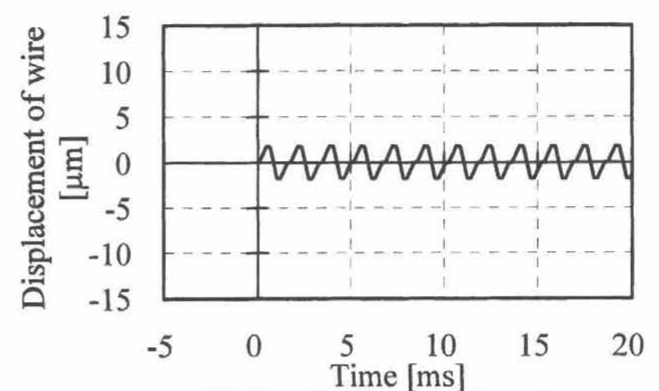

(b) Depth of cut of $0 \mu \mathrm{m}$

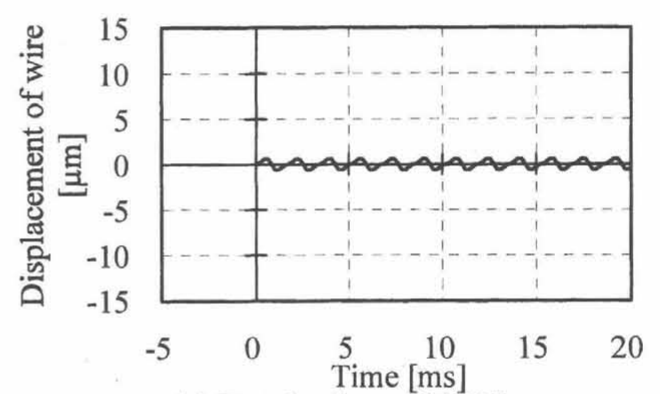

(c) Depth of cut of $3000 \mu \mathrm{m}$

Fig. 11 Wire movement calculated when workpiece is copper

respectively. The horizontal axis shows the time after the single pulse current was supplied to the wire. The direction of the initial movement of the wire was toward the workpiece. This fact indicates that the electromagnetic force was attractive when workpiece was steel. The amplitude of wire oscillation was largest at the depth of cut of $200 \mu \mathrm{m}$ corresponding to the calculated electromagnetic force which is maximum at the same position.

The wire movements measured at the depth of cut of $-100 \mu \mathrm{m}, 0 \mu \mathrm{m}$, and $3000 \mu \mathrm{m}$ in the case of copper workpiece are shown in Fig. 9 (a), (b), and (c), respectively. The wire started moving departing from the workpiece. This fact indicates that the electromagnetic force is repulsive for the copper workpiece. Since the absolute value of electromagnetic force for the copper workpiece was smaller than the steel workpiece, the magnitude of the wire movement was smaller with the copper 
workpiece.

\subsection{Calculation of wire movement}

Wire movements at the attached position of the optical sensor were calculated under the same conditions as in the previous section. The model of analysis of wire movement was a string vibration model in which the wire was supported at the upper and lower wire guides. The electromagnetic force calculated was applied to the wire uniformly where the wire faced the workpiece. Damping of the wire was ignored and the wire tension was $3 \mathrm{~N}$.

Wire movements calculated at the depth of cut of $-100 \mu \mathrm{m}, 200 \mu \mathrm{m}$, and $3000 \mu \mathrm{m}$ for the steel workpiece are shown in Fig. 10 (a), (b), and (c), respectively. Wire movements at the depth of cut of $-100 \mu \mathrm{m}, 0 \mu \mathrm{m}$, and $3000 \mu \mathrm{m}$ for the copper workpiece are shown in Fig. 11 (a), (b), and (c), respectively. All the analytical results agree very well with the experimental results shown in the previous section, verifying the electromagnetic forces calculated in this study.

\section{CONCLUSIONS}

The electromagnetic force applied to the wire during the rough cutting of WEDM was analyzed by FEM considering electromagnetic induction. Wire movement was then calculated when a single pulse discharge current used in rough cutting was supplied to the wire assuming that only electromagnetic force is applied to the wire. Furthermore, wire movement when only electromagnetic force was applied to the wire was measured. From the comparison between experimental and analyzed results, the following findings were obtained:

1) With the steel workpiece, the static electromagnetic force is larger than the dynamic force and the resultant electromagnetic force is attractive. With the copper workpiece, the dynamic electromagnetic force is dominant and repulsive.

2) The electromagnetic force is largest at the depth of cut of about $200 \mu \mathrm{m}$ and $0 \mu \mathrm{m}$ when the workpiece is steel and copper, respectively. The force decreases thereafter with the depth of cut and remains constant when the depth of cut is over several millimeters.

3) The wire movements measured in the experiments agreed very well with the wire movements analyzed, validating the electromagnetic forces calculated in this study.

4) Under the rough cutting conditions used in this study, the impulse of the electromagnetic force was larger than that of the electrostatic force for the steel workpiece, indicating that considering the electromagnetic force is required in the geometrical simulation of rough cutting.

\section{REFERENCES}

1) Rudolf Panschow: Über die Kräfte und ihre Wirkungen beim electroerosiven Schneiden mit Drahtelektrode, Dissertation, T. U. Hannover, (1974)

2) Willem L. Dekeyser, R. Snoeys: Geometrical Accuracy of Wire-EDM, Proc. of ISEM, 9, (1989), 226-232

3) H. Obara, Y. Makino, T. Ohsumi: Single Discharging Force and Single Machining Volume of Wire EDM, Proc. of ISEM, 11, (1995), 85-93

4) H. Yamada, N. Mohri, K. Furutani, N. Saito, T. Magara: Transient Response of Wire Vibration System in Wire Electrical Discharge Machining, J. of JSPE, 63, 11, (1997), 1548-1552 (in Japanese)

5) H. Yamada, N. Mohri, H. Takezawa, K. Furutani, T. Magara: Influence of Single Discharge Impulse on Vibration of Tool Electrode in Wire Electrical Discharge Machining, J. of JSPE, 64, 2, (1998), 297-301 (in Japanese)

6) F. Han, M. Kunieda, T. Sendai, Y. Imai: High Precision Simulation of WEDM Using Parametric Programming, Annals of the CIRP, 51, 1, (2002), 165-168

7) H. Obara, N. Ishizu, T. Kawai, T. Ohsumi, T. Hayashi: Simulation of Wire EDM (3rd Report) -Accuracy of Finish Cut-, J. of JSEME, 34, 75, (2000), 30-37 (in Japanese)

8) H. Obara: The Analysis of Wire Break Down Limitation on Wire EDM (1st Report; Analysis of Water Flow in Cut Groove), J. of JSEME, 22, 44, (1989), 10-22 (in Japanese)

9) N. Kinoshita, M. Fukui, Y. Kimura: Study on Wire-EDM: In-process Measurement of Mechanical Behaviour of Electrode-Wire, Annals of the CIRP, 33, 1, (1984), 89-92

10) S. Tomura, M. Kunieda: Analysis of Electromagnetic Force in Wire-EDM, submitted to Precision Engineering

11) H. Obara, T. Ishizu, T. Ohsumi, Y. Iwata, Simulation of Wire EDM, Proc. of ISEM, 12, (1998), 99-108

12) M. Nishikawa, M. Kunieda, In-process measurement of wire behavior in wire-EDM, Proc. of Spring Meeting of JSPE, (2007), 491-492 (in Japanese) 